\title{
The relationship between college athletes' health literacy and COVID-19 anxiety levels
}

\author{
Sinan Uğraş ${ }^{1 \mathrm{ABCDE}}$, Ahmet E. Sağin ${ }^{2 \mathrm{ABCDE}}$, Ömer Karabulut ${ }^{3 \mathrm{BDE}}$, Gökmen Özen ${ }^{1 \mathrm{ABCDE}}$ \\ ${ }^{1}$ Çanakkale Onsekiz Mart University, Turkey \\ ${ }^{2}$ Inonu University, Turkey \\ ${ }^{3}$ Piri Reis Secondary School, Ministry of Education, Turkey
}

Authors' Contribution: A - Study design; B - Data collection; C - Statistical analysis; D - Manuscript Preparation; E - Funds Collection

\begin{abstract}
Background Health literacy is the ability to access health information, understand, evaluate and apply health information. and Study The health literacy of athletes may be determinant in the understanding of the COVID-19 pandemic process

Aim and in the level of the impact of this health-related anxiety factor. Therefore, the aim of this study is to examine whether there is a relationship between college athletes' COVID-19 anxiety levels and their health literacy levels during the COVID-19 pandemic.

Material College athletes between the ages of 18 and 32 participated in the study and the average age was 24.2. A and total of 234 elite collage athletes participated in the study. 133 of the participants were males and 101 were Methods females. COVID-19 Anxiety Scale was used to determine the COVID-19 anxiety states and Health Literacy index was used to the level of health literacy of the participants in the COVID-19 pandemic process. Pearson correlation analysis and stepwise regression analysis were performed for statistical analyses. Significance level in analysis has been accepted as p. $<05$.

Results: $\quad$ Our findings revealed that there were significant relationships between elite athletes' health literacy subdimension scores and COVID-anxiety level. In addition, it was determined that access to information and understanding information sub-dimensions from health literacy sub-dimensions predicted elite college athletes' the COVID-19 anxiety level at 21.2\%. As a result, elite college athletes had low levels of anxiety against COVID-19, and this situation associated with their high level of health literacy.

Conclusions The increase of elite college athletes' the level of health literacy will decrease their anxiety levels. It will be beneficial to implement training programs that can increase their health literacy levels in order to reduce the impact of the unexpected health crisis due to COVID-19, especially the anxiety levels of college athletes.

Keywords: anxiety, college athletes, COVID-19, health, health literacy.
\end{abstract}

\section{Introduction}

With the increase in COVID-19 cases worldwide, countries have had to take many measures, social distance rules were established, people were put under quarantine. Many institutions and organizations (schools and workplaces etc.) were closed within the scope of these measures [1]. Due to the pandemic, people have experienced unprecedented stress, anxiety, depression, fear in their homes and continue to live [2]. In previous scientific studies, it has been revealed that staying indoors for a long time increases the stress level of people and causes psychological negativity [3]. Considering that people stay indoors for a long time during the epidemic process, it is normal for them to experience similar mental problems [4]. In particular, anxiety emerged as a common mental health problem during the COVID-19 outbreak [5]. Because uncertainty is an important factor in increasing people's anxiety level [6]. A study in the literature reveals that the COVID-19 outbreak alone increases the anxiety level in humans between $28 \%$ and $33 \%$ [7].

Undoubtedly, the pandemic has caused many negative effects on people, and it seems that this situation will likely continue for a while. This unusual situation has physical, (c) Sinan Uğraş, Ahmet E. Sağin, Ömer Karabulut,

Gökmen Özen, 2021

doi:10.15561/20755279.2021.0105 psychological and behavioral consequences on athletes [8]. The pandemic has also affected the lives, planning and routines of athletes. Athletes experience difficulties and problems such as career disruption, social isolation, an unusually uncertain process, staying away from teammates [9]. The situations such as uncertainty when the epidemic threat will end, increased information pollution about the epidemic and its effects, a mandatory reduction in social relations, the recommendation of home isolation unless it is necessary, and the introduction of different types of bans are likely to affect the mental health of athletes. As a matter of fact, there are studies showing that athletes are also negatively affected by this process $[10,11,12]$. Pillay et al [13], in their study with elite and semi-elite South African athletes, found that athletes worked on their own (61\%), their sleep patterns changed significantly (79\%), consumed excessive amounts of carbohydrates (76\%), and many athletes experienced depressive feelings (52\%) [13]. In this process, an important factor that will affect the anxiety levels of both elite and non-elite athletes is health literacy.

Health literacy is the ability to access health information, understand, evaluate and apply health information [14]. According to Nutbeam [15], health literacy consists of functional, interactive and critical domains. Functional 
domain refers to the basic skills required to read and write health information. While the interactive domain represents advanced skills that enable individuals to extract health information and gain meaning, the critical domain refers to the empowerment of the individual and society by critically evaluating health information Low level of health literacy is an important problem all over the world. In a study conducted in 2003, it is estimated that approximately $36 \%$ of the population in the United States has limited health literacy [16]. Although it varies from country to country in Europe, it has been found that the health literacy of $12 \%$ of the population is insufficient and $47 \%$ of the population is not at a sufficient level [17]. Similarly, there is a limited health literacy in Japan, behind Europe [18]. These studies actually show that health literacy is a current issue all over the world.

When we look specifically at athletes, it shows that health literacy is at a higher level among athletes. The fact that sports environments and clubs offer a healthpromoting environment may have contributed to the emergence of such a difference [19, 20]. Although health literacy is higher in athletes, the long stay of athletes in home environments during the COVID-19 process increases their anxiety levels and the risk of getting sick [21]. In the statement of the International Society of Sports Psychology, it is recommended to increase the health literacy of elite athletes for mental health [22]. Castaldelli et al [23] stated that low health literacy in elite athletes causes them to experience more mental problems. It is stated in the studies conducted that the health literacy level of individuals may be an important factor in reducing anxiety [24, 25].

In the light of all these data, the COVID-19 pandemic process is one of the important factors affecting the anxiety levels of both elite athletes and non-elite athletes. On the other hand, the health literacy of athletes may be determinant in the understanding of the COVID-19 pandemic process and in the level of the impact of this health-related anxiety factor. In order for athletes to spend this period with less physical and psychological losses, anxiety and factors that affect anxiety should be examined. In this context, the aim of the study is to examine the relationship between the health literacy levels of elite athletes and their COVID-19 anxiety levels.

\section{Materials and Methods}

\section{Participants}

The distribution of elite college athletes participating in the study according to their sports branches was as follows. Those who do individual sports make up 29,9\% of the participants, those who do team sports make up $35 \%$ of the participants, those who do net and racket sports make up $25,6 \%$ of the participants, those who do combat sports make up $9,4 \%$ of the participants. In total, of 234 athletes participated in the study. While $56.8 \%$ (n $=133)$ of the study were male athletes, $43.2 \%(n=101)$ were female athletes. College athletes between the ages of 18 and 32 participated in the study and the average age was 24.2. While collecting the data, attention was paid to the fact that the participants were still in the training and competition period, and the data were collected during the COVID-19 pandemic process.

\section{Research Design}

Relational screening model was used to examine the relationship between the health literacy levels of elite athletes and their COVID-19 anxiety levels. Relational screening research are studies that give an idea about the cause-effect probability among the objective variables and the relationship between the variables [26]. In this study, the relationship between the 4 sub-dimensions of the health literacy scale and Covid-19 anxiety was examined. This study was conducted according to the criteria set by the Declaration of Helsinki and ethical standards in sport and exercise science research [27].

Data collection tools

"Health Literacy Scale" and "Short Form of "Coronavirus Anxiety Scale" were used as data collection tools in the study.

Health literacy scale: Toçi, Bruzari and Sorenson converted the 47-item HLS-E.U (Health Literacy index) form, developed by Sørensen, into a 25-item form by working together later [28, 29]. The scale, whose adaptation was made by Aras and Temel [30], which consists of 25 items and 4 sub-dimensions was used. Cronbach alpha value of "Access to Information" dimension was 0.807 , cronbach alpha value of "Understanding Information" dimension was 0.734 , cronbach alpha value of "Value Assessment / Evaluation" was 0.821, and Cronbach alpha value of "Implementation / Use" dimension was 0.816 . It has a 5-point likert structure such as "5: I have no difficulty, 4: I have little difficulty, 3: I have some difficulty, 2: I have many difficulties, 1: I cannot do it / I have no talent / impossible".

Short form of Coronavirus Anxiety Scale: In the study the scale form, which was developed by Lee [31] to describe possible cases of dysfunctional anxiety associated with the COVID-19 crisis and adapted to Turkish by Biçer et al [32], was used . It is a 5-point Likert-type scale as "never", "rare, less than a day or two", "a few days", "more than 7 days" and "almost every day in the last two weeks". Cronbach alpha value of the scale was determined to be 0.816 .

\section{Statistical analysis}

After the data were loaded into the Jamovi 1.6.9 statistical program, analyzes were performed. The skewness and kurtosis values were examined for the normality analysis of the data. After it was determined that the data was distributed between +1.5 and -1.5 , which is the normal distribution condition [33], Pearson correlation analysis and stepwise regression analysis were performed. Before performing regression analysis, the suitability of the data for regression analysis was tested. It was investigated whether there was a multicollinearity problem. Multicollinearity occurs when independent variables have a high correlation such as .80-.90 (34). Correlation values among variables were found to be between 0.704 and -0.238 . In order to determine whether there is a multicollinearity problem, the VIF value 
should also be less than 10 [33]. VIF values were found to vary between 1.0 and 1.40 . In the light of these data, it was determined that the multiple regression analysis conditions were met for this study. Significance level in analysis has been accepted as p. 05 .

\section{Results}

When Table 1 was examined, it was seen that the average and standard deviation values of the athletes participating in the study are $4.39 \pm 0.567$ in the dimension of access to information, $4.34 \pm 0.504$ in the dimension of understanding information, $4.32 \pm 0.559$ in the assessment / evaluation dimension, $4.32 \pm 0.594$ in the implementation/ use dimension, and $1.51 \pm 0.639$ in the coronavirus anxiety. While the skewness value varied between -0.576 and 1.14 , the kurtosis value was found to be between -0.0154 and 1.18 .

Partial correlation values of the relationship between the health literacy sub-dimensions of athletes and coronavirus anxiety scores were calculated, and the findings are presented in Table 2. It is seen that there is a significant negative correlation between access to information and coronavirus anxiety $(\mathrm{r}=-0.431, \mathrm{p}<.001)$, between understanding information and coronavirus anxiety $(\mathrm{r}=-0.367, \mathrm{p}<.001)$, between assessment / evaluation and coronavirus anxiety $(\mathrm{r}=-0.238, \mathrm{p}<.001)$, and finally between implementation/ use and coronavirus anxiety $(\mathrm{r}=-0.295, \mathrm{p}<.001)$.

As a result of the partial correlation analysis made in Table 2, a stepwise regression analysis was performed on coronavirus anxiety, which was determined to be related to health literacy, and the results obtained are presented in Table 3 .

When Table 3 was examined, it was found that access to information, which is a health literacy sub-dimension, predicted coronavirus anxiety $(\mathrm{r} 2=0.186=\mathrm{f}=53.0, \mathrm{p}$ $<.0001$ ) at a rate of $18.6 \%$. In the second step of stepwise regression, re-analysis was performed by including the dimension of understanding information. As a result of this analysis, it was concluded that the dimensions of access to information and understanding information predicted coronavirus anxiety $(\mathrm{r} 2=0.212=\mathrm{f}=31.1, \mathrm{p}<.05)$ at a rate of $21.2 \%$. Assessment / evaluation and implementation dimensions were not included in the stepwise regression since they did not predict significantly.

Table 1. The Averages, Skewness and Kurtosis Values of the Health Literacy Sub-Dimensions and Coronavirus Anxiety Levels of the Athletes Participating in the Study

\begin{tabular}{|c|c|c|c|c|c|}
\hline Dimensions & $\mathbf{N}$ & $\overline{\mathbf{x}}$ & S.D & Skewness & Kurtosis \\
\hline Access to Information & 234 & 4.39 & 0.567 & -0.864 & 0.0741 \\
\hline Understanding Information & 234 & 4.34 & 0.504 & -1.05 & 1.18 \\
\hline $\begin{array}{l}\text { Assessment/ } \\
\text { Evaluation }\end{array}$ & 234 & 4.32 & 0.559 & -0.763 & 0.522 \\
\hline $\begin{array}{l}\text { Implementation/ } \\
\text { Use }\end{array}$ & 234 & 4.32 & 0.594 & -0.576 & -0.587 \\
\hline $\begin{array}{l}\text { Coronavirus } \\
\text { Anxiety }\end{array}$ & 234 & 1.51 & 0.639 & 1.14 & -0.0154 \\
\hline
\end{tabular}

Table 2. Analysis Results of Pearson Correlation Between Health Literacy Sub-dimensions and Coronavirus Anxiety

\begin{tabular}{|c|c|c|c|c|c|}
\hline Dimensions & $\begin{array}{l}\text { Access to } \\
\text { Information }\end{array}$ & $\begin{array}{l}\text { Understanding } \\
\text { Information }\end{array}$ & $\begin{array}{l}\text { Assessment/ } \\
\text { Evaluation }\end{array}$ & $\begin{array}{l}\text { Implementation/ } \\
\text { Use }\end{array}$ & $\begin{array}{l}\text { Coronavirus } \\
\text { Anxiety }\end{array}$ \\
\hline Access to Information & - & & & & \\
\hline Understanding Information & $0.537^{* * *}$ & - & & & \\
\hline $\begin{array}{l}\text { Assessment/ } \\
\text { Evaluation }\end{array}$ & $0.368 * * *$ & $0.684 * * *$ & - & & \\
\hline $\begin{array}{l}\text { Implementation/ } \\
\text { Use }\end{array}$ & $0.374 * * *$ & $0.582^{* * *}$ & $0.704 * * *$ & - & \\
\hline $\begin{array}{l}\text { Coronavirus } \\
\text { Anxiety }\end{array}$ & $-0.431^{* * *}$ & $-0.367 * * *$ & $-0.238 * * *$ & $-0.295 * * *$ & - \\
\hline
\end{tabular}

Note. $* p<.05, * * p<.01, * * * p<.001$ 
Table 3. Regression Analysis Results Related to the Prediction of Health Literacy Sub-Dimensions for Coronavirus Anxiety Level

\begin{tabular}{lllllllll}
\hline Predictor & Estimate & SE & $\mathbf{T}$ & $\mathbf{P}$ & $\begin{array}{l}\text { Stand. } \\
\text { Estimate }\end{array}$ & $\mathbf{R}$ & $\mathbf{R}^{\mathbf{2}}$ & $\mathbf{F}$ \\
\hline Intercept & 3.650 & 0.2956 & 12.35 & .001 & 0.431 & 0.431 & 0.186 & 53.0 \\
Access to Information & -0.486 & 0.0667 & -7.28 & .001 & & & & \\
Intercept & 4.190 & 0.3517 & 11.92 & .001 & & & & \\
Access to Information & -0.371 & 0.0780 & -0.524 & .001 & -0.329 & 0.460 & 0.212 & 31.1 \\
$\begin{array}{l}\text { Understanding } \\
\text { Information }\end{array}$ & -0.241 & 0.0877 & -0.414 & 0.006 & -0.190 & & & \\
\hline
\end{tabular}

\section{Discussion}

In this study, the relationship between the health literacy levels of elite athletes and their covid-19 anxiety levels was examined. According to the results of statistical analysis, it is seen that the health literacy average scale scores of the athletes participating in the study are quite high, while coronavirus anxiety is low. Contrary to our study, in studies in which the anxiety levels of elite athletes were measured in the literature, it was found that the anxiety levels of elite athletes were high [35, 36, 37]. Many elite athletes spend this period in the home environment uncertainly, they have to train on their own and without supervision, the dates of the competition are not clear, these situations make this process difficult for the athletes [35, 36]. Hull et al [37] state that the sudden cancellation and postponement of international competitions (Tokyo Olympics, etc.) for which elite athletes have been prepared for a long time, and the subsequent isolation of the athletes at home and staying away from the training process cause the anxiety levels of athletes to increase. In the study conducted by Fronso et al [40] with 1132 athletes, it was revealed that the COVID-19 epidemic increased the stress level of athletes significantly on condition that it was more in nonelite athletes. Contrary to these studies, studies that are in parallel with our study are also included in the literature $[11,41]$. Clemente et al [11], as the reason for that the elite athletes were less affected in this process, stated that these athletes have psychological flexibility, they can receive institutional support and they can cope with problems more. At the same time, an important factor in the low anxiety level of athletes may be that they continue to do sports even at home. Because, in studies conducted, it has been determined that individuals who stay in the home environment and exercise during the isolation process significantly decrease their anxiety levels [42, 43].

Another finding of our study shows that there is a significant negative correlation between the health literacy of athletes and their coronavirus anxiety scores. It was concluded that access to information, which is the health literacy sub-dimension, predicts coronavirus anxiety by $18.6 \%$, and when the dimension of understanding information is added to the analysis, it predicts the coronavirus anxiety level by $21.2 \%$. When athletes' level of access to information is added to their level of understanding of the information they have reached, it can be concluded that it positively predicts their anxiety levels. It can be stated that athletes' access to the right sources of information and their level of understanding these are important. Therefore, we can say that health literacy plays an important role in low anxiety levels of elite athletes. The low level of health literacy among elite athletes may lead to more mental problems [23]. In this respect, it can be stated how important the health literacy level is for athletes.

In the studies conducted, it was emphasized that athletes should be trained in health literacy in order to prevent the psychological problems caused by the COVID-19 epidemic and to improve themselves [13, 4447]. Gorczynski et al [48] states that health literacy can play an important role in the development of the mental health of elite athletes and in eliminating the disorders if any. In order for the individual to make healthy decisions in sickness or in health, the individual needs health literacy skills [49]. Kickbusch et al [50] state that health literacy is more important than individuals' reading skills, and the ability to understand and process complex information is the main point. Experts provide recommendations for individuals with high levels of anxiety to increase their health literacy. Because it is known to play an important role in reducing anxiety [51, 52]. In another study, it was determined that health literacy specific to infectious diseases predicted $32.7 \%$ of anxiety levels in individuals [25]. Although we have been exposed to some inevitable adversities during the pandemic process, we can say that elite athletes are well equipped to manage this process well in our study. In fact, our findings indicate that their anxiety levels are low and they have the necessary health literacy skills.

\section{Conclusion}

It was observed that elite college athletes had low anxiety levels during the COVID-19 outbreak. It has been concluded that an important factor in low anxiety levels of elite college athletes is health literacy. There is a significant negative correlation between health literacy and anxiety, and health literacy (dimensions of access to information and understanding information) predicts coronavirus anxiety by approximately $21 \%$. It may be interesting to compare the impact of the COVID-19 
crisis on non-elite athletes as well as athletes in the same sports branch in future studies. Programs can be developed to increase health literacy among athletes. It will be beneficial to implement training programs that can increase their health literacy levels in order to reduce the impact of the unexpected health crisis due to COVID-19, especially the anxiety levels of athletes.

\section{Funding}

The authors have no funding to disclose.

\section{Conflicts of Interest}

The authors declare that they have no conflict of interest.

\section{References}

1. Punn NS, Sonbhadra SK, Agarwal S. Monitoring COVID-19 social distancing with person detection and tracking via finetuned YOLO v3 and Deepsort techniques. ArXiv:200501385 [Cs] 2020.

2. Li S, Wang Y, Xue J, Zhao N, Zhu T. The impact of COVID-19 epidemic declaration on psychological consequences: a study on active Weibo users. Int. J. Environ. Res. Public Health 2020; 17(6): 2032. https://doi.org/10.3390/ijerph17062032

3. Strewe C, Muckenthaler F, Feuerecker M, Yi B, Rykova M, Kaufmann I, et al. Functional changes in neutrophils and psychoneuroendocrine responses during 105 days of confinement.JournalofAppliedPhysiology, 2015;118:1122-7. https://doi.org/10.1152/japplphysiol.00755.2014

4. Brooks SK, Webster RK, Smith LE, Woodland L, Wessely S, Greenberg N, et al. The psychological impact of quarantine and how to reduce it: rapid review of the evidence. The Lancet, 2020;395:912-20. https://doi.org/10.1016/S0140-6736(20)30460-8

5. Wang $\mathrm{C}$, Pan R, Wan X, Tan $\mathrm{Y}, \mathrm{Xu} \mathrm{L}$, Ho CS, et al. Immediate Psychological Responses and Associated Factors during the Initial Stage of the 2019 Coronavirus Disease (COVID-19) Epidemic among the General Population in China. IJERPH 2020;17:1729. https://doi.org/10.3390/ijerph17051729

6. de Oliveira Araújo FJ, de Lima LSA, Cidade PIM, Nobre CB, Neto MLR. Impact of Sars-Cov-2 and its reverberation in global higher education and mental health. Psychiatry Res, 2020;288:112977. https://doi.org/10.1016/j.psychres.2020.112977

7. Luo M, Guo L, Yu M, Jiang W, Wang H. The psychological and mental impact of coronavirus disease 2019 (COVID-19) on medical staff and general public - a systematic review and meta-analysis. Psychiatry Res. 2020;291:113190. https://doi.org/10.1016/j.psychres.2020.113190

8. Lim MA, Pranata R. Sports activities during any pandemic lockdown. Ir J Med Sci, 2021;190:447-51. https://doi.org/10.1007/s11845-020-02300-9

9. SchinkeR,PapaioannouA,HenriksenK, SiG,ZhangL,HaberlP. Sport psychology services to high performance athletes during COVID-19. Int J Sport Exerc Psychol, 2020; 18(3): 269-72. https://doi.org/10.1080/1612197X.2020.1754616

10.Paoli A, Musumeci G. Elite athletes and Covid-19 lockdown: future health concerns for an entire sector. $J$ Funct Morphol Kinesiol. 2020;5:30. https://doi.org/10.3390/jfmk5020030

11.Clemente-Suárez VJ, Fuentes-García JP, de la Vega Marcos R, Martínez Patiño MJ. Modulators of the personal and professional threat perception of Olympic athletes in the actual COVID-19 crisis. Front. Psychol 2020; 11:1985. https://doi.org/10.3389/fpsyg.2020.01985

12.Pons J, Ramis Y, Alcaraz S, Jordana A, Borrueco M, Torregrossa M. Where Did All the Sport Go? Negative Impact of COVID-19 Lockdown on Life-Spheres and Mental Health of Spanish Young Athletes. Front Psychol. 2020;11:611872. https://doi.org/10.3389/fpsyg.2020.611872

13.Pillay L, Janse van Rensburg DCC, Jansen van Rensburg A, et al. Nowhere to hide: the significant impact of coronavirus disease 2019 (COVID-19) measures on elite and semi-elite South African athletes. J Sci Med Sport, 2020;23:670-9. https://doi.org/10.1016/j.jsams.2020.05.016

14.Okan O, Bollweg TM, Berens EM, Hurrelmann K, Bauer U, Schaeffer, D. Coronavirus-related health literacy: A crosssectional study in adults during the COVID-19 infodemic in Germany.Int.J.Environ.Res.PublicHealth, 2020;17(15):5503. https://doi.org/10.3390/ijerph17155503

15.Nutbeam, D. Health literacy as a public health goal: a challenge for contemporary health education and communication strategies into the 21 st century. Health Promot Int. 2000; 15(3): 259-267.

16.Kutner M, Greenburg E, Jin Y, Paulsen C. The Health Literacy of America's Adults: Results from the 2003 National Assessment of Adult Literacy. NCES 2006-483. National Center for Education Statistics. 2006:1-60.

17.Sørensen K, Pelikan JM, Röthlin F, Ganahl K, Slonska Z, Doyle G, et al. Health literacy in Europe: comparative results of the European health literacy survey (HLS-EU). Eur J Public Health, 2015;25:1053-8. https://doi.org/10.1093/eurpub/ckv043

18. Nakayama K, Osaka W, Togari T, Ishikawa H, Yonekura Y, SekidoA, et al. Comprehensive health literacy in Japan is lower than in Europe: a validated Japanese-language assessment of health literacy. BMC Public Health. 2015;15:505. https://doi.org/10.1186/s12889-015-1835-x

19.Bapat S, Jorm AF, Lawrence K. Evaluation of a mental health literacy training program for junior sporting clubs. Australas Psychiatry, 2009; 17: 475-479. https://doi.org/10.1080/10398560902964586

20.Paakkari L, Kokko S, Villberg J, Paakkari O, Tynjälä J. Health literacy and participation in sports club activities among adolescents. Scand. J. Public Health, 2017; 45(8), 854-860. https://doi.org/10.1177/1403494817714189

21.Ranasinghe C, Jayawardena R, Palihawadana V. Kick start training during the COVID-19 pandemic-Challenges of the sporting community. Sri Lankan Journal of Sports and Exercise Medicine 2020; 2(1): 1-9.

22.Henriksen K, Schinke R, Moesch K, McCann S, Parham $\mathrm{WD}$, Larsen $\mathrm{CH}$, et al. Consensus statement on improving the mental health of high performance athletes. International Journal of Sport and Exercise Psychology, 2020;18:553-60. https://doi.org/10.1080/1612197X.2019.1570473

23.Castaldelli-Maia JM, Gallinaro JG de M e, Falcão RS, Gouttebarge V, Hitchcock ME, Hainline B, et al. Mental health symptoms and disorders in elite athletes: a systematic review on cultural influencers and barriers to athletes seeking treatment. Br J Sports Med, 2019;53:707-21. https://doi.org/10.1136/bjsports-2019-100710

24.Kıraç R, Öztürk YE. The relationship between public health literacy level and health anxiety. Journal of Sociological Research, 2020; 23(2): 214-243. https://doi.org/10.18490/sosars.819000 
25.Xiao X, Xiao J, Yao J, Chen Y, Saligan L, Renynolds NR, et al. The Role of Resilience and Gender in Relation to Infectious-Disease-Specific Health Literacy and Anxiety During the COVID-19 Pandemic. Neuropsychiatr Dis Treat, 2020;16:3011-21. https://doi.org/10.2147/NDT.S277231

26.Fraenkel JR, Wallen NE, Hyun HH. How To Design And Evaluate Research in Education. McGraw-Hill; 2012

27.Harriss D, Atkinson G. Ethical Standards in Sport and Exercise Science Research: 2016 Update. Int J Sports Med, 2015; 36 (14): 1121-1124.

28.Sørensen K, Van den Broucke S, Pelikan JM, Fullam J, Doyle $\mathrm{G}$, Slonska Z, et al. Measuring health literacy in populations: illuminating the design and development process of the European Health Literacy Survey Questionnaire (HLS-EU-Q). BMC Public Health, 2013;13:948. https://doi.org/10.1186/1471-2458-13-948

29.Toçi E. Health Literacy and Socioeconomic Characteristics among Older People in Transitional Kosovo. $\mathrm{Br} J$ Med Med Res, 2013;3:1646-58. https://doi.org/10.9734/BJMMR/2013/3972

30.Aras Z, Temel AB. Evaluation of the Validity and Reliability of the Turkish Form of the Health Literacy Scale. F.N. Hem. Derg 2017; 25(2): 85-94. (In Turkish).

31.Lee DH, Kim JY, Kang HS. The emotional distress and fear of contagion related to Middle East Respiratory Syndrome (MERS) on general public in Korea. Korean J Psychol Gen 2016; 35(2): 355-383.

32.Biçer İ, Çakmak C, Demir H, Kurt ME. Coronavirus Anxiety Scale Short Form: Turkish Validity and Reliability Study. Anatol Clin, 2020; 25(Suppl.1): 216-225. https://doi.org/10.21673/anadoluklin.731092

33. Tabachnick BG, Fidell LS, Ullman JB. Using multivariate statistics. Vol. 5. Boston, MA: Pearson; 2007.

34.Can A. Quantitative data analysis in scientific research process with SPSS. Ankara: Pegem Academy; 2014. (In Turkish).

35.Davis PA, Gustafsson H, Callow N, Woodman T. Written Emotional Disclosure Can Promote Athletes' Mental Health and Performance Readiness During the COVID-19 Pandemic. Front Psychol. 2020; 11: 3304. https://doi.org/10.3389/fpsyg.2020.599925

36. Reardon CL, Bindra A, Blauwet C, Budgett R, Campriani N, Currie A, et al. Mental health management of elite athletes during COVID-19: a narrative review and recommendations. Br J Sports Med, 2020:bjsports-2020-102884. https://doi.org/10.1136/bjsports-2020-102884

37.Toresdahl BG, Asif IM. Coronavirus disease 2019 (COVID19): considerations for the competitive athlete. Sports Health, 2020; 12:221-224. https://doi.org/10.1177/1941738120918876

38. Sarto F, Impellizzeri FM, Spörri J, Porcelli S, Olmo $\mathrm{J}$, Requena $\mathrm{B}$, et al. Impact of Potential Physiological Changes due to COVID-19 Home Confinement on Athlete Health Protection in Elite Sports: a Call for Awareness in Sports Programming. Sports Med, 2020;50:1417-9. https://doi.org/10.1007/s40279-020-01297-6

39. Hull JH, Loosemore M, Schwellnus M. Respiratory health in athletes: facing the COVID-19 challenge. Lancet Respir Med, 2020;8:557-8. https://doi.org/10.1016/S2213-2600(20)30175-2 40.di Fronso S, Costa S, Montesano C, Di Gruttola F, Ciofi EG, Morgilli L, et al. The effects of COVID-19 pandemic on perceived stress and psychobiosocial states in Italian athletes. International Journal of Sport and Exercise Psychology, 2020:1-13. https://doi.org/10.1080/1612197X.2020.1802612

41.Fuentes-García JP, Martínez Patiño MJ, Villafaina S, Clemente-Suárez V. The Effect of COVID-19 confinement in behavioral, psychological, and training patterns of chess players. Front. Psychol 2020;11:1812. https://doi.org/10.3389/fpsyg.2020.01812

42.Maugeri G, Castrogiovanni P, Battaglia G, Pippi R, D'Agata V, Palma A, et al. The impact of physical activity on psychological health during Covid-19 pandemic in Italy. Heliyon, 2020;6:e04315. https://doi.org/10.1016/j.heliyon.2020.e04315

43.Woods JA, Hutchinson NT, Powers SK, Roberts WO, Gomez-Cabrera MC, Radak Z, et al. The COVID-19 pandemic and physical activity. Sports Medicine and Health Science, 2020;2:55-64. https://doi.org/10.1016/j.smhs.2020.05.006

44.Boris G, Stéphane T. Health for Performance: a necessary paradigm shift for youth athletes. Schweizerische Zeitschrift für Sportmedizin \& Sporttraumatologie, 2020; 68(2). https://doi.org/10.34045/SEMS/2020/16

45.Håkansson A, Moesch K, Jönsson C, Kenttä G. Potentially ProlongedPsychologicalDistress fromPostponedOlympicand Paralympic Games during COVID-19 - Career Uncertainty in Elite Athletes. Int. J. Environ. Res. Public Health, 2021, 18, 2. https://doi.org/10.3390/ijerph18010002

46.Raiola G,Aliberti S, Esposito G,Altavilla G, D'Isanto T, D'Elia F. How has the Practice of Physical Activity Changed During the COVID-19 Quarantine? A Preliminary Survey. Teoriâ ta Metodika Fìzičnogo Vihovannâ, 2020; 20(4), 242-247. https://doi.org/10.17309/tmfv.2020.4.07

47.Zureigat A, Fattah OA. Effect of the Leisure Activities on the Level of Psychological stress among the elderly during the Coronavirus Outbreak. Phys Activ Rev, 2021; 9(1): 70-78. https://doi.org/10.16926/par.2021.09.09

48.Gorczynski P, Currie A, Gibson K, Gouttebarge V, Hainline B, Castaldelli-Maia JM, et al. Developing mental health literacy and cultural competence in elite sport. Journal of Applied Sport Psychology, 2020:1-15. https://doi.org/10.1080/10413200.2020.1720045

49.Carbone ET, Zoellner JM. Nutrition and health literacy: a systematic review to inform nutrition research and practice. J Acad Nutr Diet, 2012; 112(2): 254-265. https://doi.org/10.1016/j.jada.2011.08.042

50.Kickbusch I, Maag D, Kris H. Health literacy. In: Heggenhougen K, Quah SR, eds. International encyclopedia of public health. Oxford: Academic Press; 2008. P. 450-62.

51.Palazzo MC, Dell'Osso B, Altamura AC, Stein DJ, Baldwin DS. Health literacy and the pharmacological treatment of anxiety disorders: a systematic review. Hum Psychopharm Clın., 2014; 29(3), 211-215. https://doi.org/10.1002/hup.2397

52.Oh HJ, Lee $H$. When do people verify and share health rumors on social media? The effects of message importance, health anxiety, and health literacy. J Health Commun, 2019; 24(11): 837-847. https://doi.org/10.1080/10810730.2019.1677824 
Information about the authors:

Sinan Uğraş; http://orcid.org/0000-0003-0792-1497; sinanugras@gmail.com; Faculty of Sport Sciences, Department of Physical Education and Sports Teaching, Çanakkale Onsekiz Mart University; Çanakkale, Turkey.

Ahmet E. Sağın; (Corresponding Author); http://orcid.org/0000-0002-4243-8276; a.enessagin@gmail.com; Inonu University, Health Sciences Institute; Malatya, Turkey.

Ömer Karabulut; https://orcid.org/0000-0002-9733-0027; omer.karabult@gmail.com; Piri Reis Secondary School, Ministry of Education; İstanbul, Turkey.

Gökmen Özen; http://orcid.org/0000-0001-5756-653X; gokmenozen44@gmail.com; Faculty of Sport Sciences, Department of Physical Education and Sports Teaching, Çanakkale Onsekiz Mart University; Çanakkale, Turkey.

Cite this article as:

Uğraş S, Sağin AE, Karabulut Ö, Özen G. The relationship between college athletes' health literacy and COVID-19 anxiety levels. Physical Education of Students, 2021;25(1):36-42.

https://doi.org/10.15561/20755279.2021.0105

This is an Open Access article distributed under the terms of the Creative Commons Attribution License, which permits unrestricted use, distribution, and reproduction in any medium, provided the original work is properly cited http://creativecommons.org/licenses/by/4.0/deed.en

Received: 16.12 .2020

Accepted: 03.02.2001; Published: 26.02.2021 